\title{
Others' environmental concern as a social determinant of green buying
}

\section{Laurent BERTRANDIAS, Leila ELGAAIED}

University of Toulouse Capitole

\begin{abstract}
:
Purpose: This study aims at achieving a better understanding of the social dimension underlying green purchasing behaviour. While the dominant approach consists in testing the effect of consumers' individual environmental concern on their behaviour, this paper assesses the impact of environmental concern ascribed to relevant others (ECARO).
\end{abstract}

Design/methodology/approach: A survey was conducted among 468 French interviewees. Using a scenario, respondents were asked to choose between two similar products: one is very fashionable but harmful to the environment and the other has comparable features with a lower negative impact on the environment.

Findings: ECARO increases the probability to choose the product with a low environmental impact over the more harmful alternative. This process is mediated by perceived social risk and self-incongruity associated with the environmentally unfriendly product.

Research limitations/implications: These results are specific to a particular cultural context and product category.

Practical implications: Environmentally responsible consumers should be encouraged to express their convictions publicly within their social network.

Social implications: This research shows that consumers tend to act consistently with the beliefs of relevant others, either to preserve their social ties or to preserve their self-congruity. Originality/value: Most studies on the determinants of green behaviour either focus exclusively on individual predispositions or tackle social influence too explicitly. By assessing the effect of ECARO instead on individual environmental concern, this research offers an original approach. Besides, the conceptualization and measurement of perceived social risk also provide interesting insights for the literature dealing with perceived risk, which tends to overlook the social dimension.

Keywords: Social norms, environmental concern, interpersonal influence, pro-environmental behaviour, social risk.

Paper type: Research paper 


\section{Others' environmental concern as a social determinant of green buying}

Since the 1970's pro-environmental behaviours have been a major topic of interest for researchers, particularly within the fields of social psychology and marketing. Given the obvious stakes related to that issue, a central theme lies in the identification of ecological behaviour determinants (e.g. Balderjahn, 1988 ; Lee and Holden, 1999 ; Stern, 2000 ; Tanner and Kast, 2003). Despite the disappointing results in terms of prediction, the notion of environmental concern emerges as one of the key motivations identified by a number of scholars to explain environmentally friendly behaviours (Bamberg, 2003). Like environmental concern, most of the predictors examined are mainly centered on the individual in the sense that they do not sufficiently reflect the influence emanating from his/her social network. Yet, it is recognized that (1) pro-environmental behaviour can be guided by conformity to norms (Nolan et al., 2001) (2) pro-environmental behaviour can be the outcome of "nonenvironmental concerns" (Lindenberg and Steg, 2007) (3) consumer choice is influenced by the preferences of others (Wind, 1976). Still, no research to our knowledge focuses on the preferences of others as a motivation for ecological purchases.

This research proposes to look into that question in order to grasp the role of social influence in the process of ecological decision making. In this study, pro-environmental purchases are indeed, essentially viewed from a normative perspective. Instead of focusing on the effect of consumers' environmental concern on their own behaviours, like a number of studies already did, this study investigates the role of environmental concern that the consumer attributes to people that can be referred to as "relevant others" "significant others", or "important others". These terms refer to special members belonging to the consumer's social network, who are important to them, whose opinion they value, who are likely to judge their choices (Wind, 1976, Krishnamurthi, 1983, Ajzen, 1991; Hopper and Nielsen, 1991). It is suggested that 
environmental concern ascribed to relevant others should lead consumers to reject the more environmentally unfriendly of two products. This paper examines two possible explanations for this tendency. First, consumers may seek to protect themselves from negative social outcomes (relationship deterioration, negative comments...). Second, they may try to protect their self-identity, which has been progressively nurtured by consumers' social referents. The first process is captured through the concept of perceived social risk. The second process is captured through the assessment of perceived incongruity between harmful product-image and self-image. Both factors (i.e. perceived social risk and product-image/self-image incongruity) are expected to mediate the link between environmental concern ascribed to relevant others and avoidance of environmentally unfriendly decisions.

The paper is structured as follows: after a brief review of previous research, highlighting the predominance of individual determinants and the need to extend previous work on social influence, the research hypotheses, methodology and findings are presented. Finally, the paper discusses the results and their implications.

\section{Social influence and pro-environmental behaviour}

Pro-environmental behaviour: an object of research mostly viewed as an individually determined phenomenon

Over the last forty years, a significant amount of research has been conducted to identify the determinants of ecological behaviour. Most of the variables that have been used to characterize environmentally conscious consumers fall into one of two broad categories known as demographics and psychographics (Shrum et al., 1994; Tanner and Kast, 2003). Research evidence appears to suggest a lack of consensus on the demographic and socioeconomic profile of environmentalists, thus raising the issue of the relevance of these 
variables (e.g. Schwepker and Cornwell, 1991). Concerning psychographic variables, some of the main concepts examined by scholars include the role of personality variables (e.g. Kinnear et al, 1974), values and beliefs (e.g. Granzin and Olsen, 1991), knowledge (e.g. Kaiser and Fuhrer, 2003), moral norms (e.g. Stern, 2000), specific attitudes (e.g. Balderjahn, 1988) and general attitudes (e.g. Bamberg, 2003). As a general attitude, environmental concern is frequently brought into play to understand the mechanism underlying pro-environmental behaviours (Schlegelmilch, et al., 1996; Bamberg, 2003; Kilbourne and Pickett, 2007).

There is one particularly striking trend: the strong predominance of individual variables. In order to understand why a consumer behaves in an environmentally friendly way, research appears to have focused almost exclusively on factors related to that specific individual. Common questions include: Is he/she concerned about the environment? Does he/she hold specific values that would predispose him/her toward environmentalism? Or is his/her behaviour influenced by his/her norms, beliefs, or level of knowledge of environmental issues? Etc. Consumers' environmentally conscious behaviours have thus been examined primarily from the individual's perspective.

\section{Normative social influence as a determinant of pro-environmental decisions}

Although previous studies have tried to take into account the role of social influence, the normative dimension underlying pro-environmental behaviours has been largely overlooked, since it has been limited mostly to theories that already consider the role of social influence (more or less explicitly). The best illustration of this trend is the frequent use of the Theory of Planned Behaviour (Ajzen, 1991) to predict the adoption of environmentally friendly actions, such as the choice of modes of transport (e.g. Heath and Gifford; 2002), recycling (e.g. Knussen et al., 2004), the intention to use renewable energy (e.g. Bang et al, 2000), purchasing behaviour (e.g. Sparks and Shepherd; 1992), etc. Technically, any research based 
on the TPB should integrate the role of normative influence and its effect on proenvironmental intentions.

However, because of the way in which the concept of subjective norms has been handled in most studies on environmentalism, the normative aspect is clearly not a central issue. As such, the concept tends to be defined very briefly and relatively superficially. A number of researchers have emphasized the limited conceptualization of subjective norms, arguing that it does not embrace all of the aspects of social influence (e.g. Terry, Hogg, and White, 1999; Thorbjørnsen et al, 2007). In a meta-analytic review of 185 studies using the TPB, Armitage and Conner (2001) concluded that subjective norms are a poor predictor of behaviour intention, which is mostly due to measurement insufficiencies but also to the restricted definition of the concept. They explain their reservations arguing that "social pressure is rarely so direct or explicit”.

Nonetheless, a number of studies have acknowledged the important role of social influence in adopting pro-environmental behaviours. For example, people tend to avoid littering when exposed to a social norm that disapproves such behaviour (Cialdini et al., 1990). Nolan et al. (2008) found that descriptive social norms were a decisive factor in energy conservation behaviours despite the fact that consumers tended to minimize their impact. In some specific cases, social motivations may be more important than individual concern. For example, an expensive green product can be mainly bought for the particular status it conveys (Griskevicius et al., 2010): it gives its owner the image of a person who favours self-sacrifice as an act of altruism instead of selfish luxury.

\section{Research hypotheses}

Influence of environmental concern ascribed to relevant others 
The limitations noted above concerning the conceptualization of social norms, together with the predominance of the approach based exclusively on the individual's viewpoint, are indicative of the work that remains to be done in order to grasp the role of social influence on ecological behaviour. The purpose of this study is to examine the determinants of ecological behaviour based on a different approach that involves focusing on the role of consumers' perceptions and beliefs regarding the environmental concern of their relevant others.

Social norms are indeed deemed to represent the values and attitudes of significant others (Hopper and Nielsen, 1991). In this respect, others' environmental concern can be viewed as "the socially accepted norm" (Schewpker and Cornwell, 1991). This idea might be worth investigating since it is often argued that social norms tend to be complied with, particularly when they are conscious or made salient (Cialdini et al, 1990).

In this study, the point of interest is not whether environmental concern is the socially accepted norm, but rather how it would affect consumers' choice if they believe that it is. In other words, if someone thinks that their friends or relatives are highly concerned about the environment, would their purchase decision-making or preferences be influenced? Individual choice may therefore reflect the preferences of relevant others rather than one's own preferences (Krishnamurthi, 1983). Thus, environmental concern conceived as a social norm may influence consumers' choices all the more so if it is associated with relevant others. Environmentally harmful products (for example a large polluting car) may enter in conflict with others pro-environmental convictions. Then, consumers should tend environmentally harmful products in favour of more neutral products as proposed in hypothesis 1.

H1: Environmental Concern Ascribed to Relevant Others (ECARO) exerts a positive impact on the probability of choosing a product with a low rather than a high environmental impact. 


\section{The mediating role of social risk}

Individuals may adopt a behaviour to play a role and to imitate others or because they aspire to be part of a specific social group (Kelman, 1961). If a consumer is aware of the environmental concern of his/her close ties, the decision to avoid non-ecological behaviour may also be motivated by the attempt to avoid negative social outcomes such as disapproval, derision, progressive rejection from the group, deterioration of self-image, etc.

Negative social consequences may be referred to as social risk. Perceived social risk has traditionally been viewed as one of the key dimensions of perceived risk (Bauer, 1960; Jacoby and Kaplan, 1972), although the concept is often overlooked or poorly conceptualized. Social risk stands out from other dimensions since it does not emanate directly from the product but from the consumer's relationships within his/her social network. The product plays the role of an intermediary, providing information about the consumer that is likely to alter the way he/she is perceived. Previous research showed that consumer's purchases depend on the (functional or symbolic) meaning associated with the product, which in turn is determined by consumer goals and the context in which the product is used (e.g. Ligas, 2000). Symbolic product meaning (self-defining) is likely to play an important role in social contexts, where possessions act as "vessels of cultural and personal meaning" used as a basis for classifying consumers (Holt, 1995). The anticipation of this alteration and its social consequences are at the origin of the perception of a social risk. Thus, perceived social risk can be defined as the anticipation of negative social consequences resulting from a decision. This study focuses more specifically on the social consequences linked to purchasing choices. Based on social influence theories (Deutsch and Gerard, 1955; Kelman, 1961, Park and Lessig, 1977, etc.), three facets of social risk can be distinguished: 1) the risk of being disapproved and/or 
criticized because of one's choices; 2) the risk of not being associated with the social group to which one aspires to belong; and 3) the risk of experiencing a psychological conflict resulting from a behaviour viewed as conflicting with the values of the group. The first facet refers to the traditional utilitarian motivation to conform to normative influence. The second facet reflects the idea that consumers use products to send a signal about who they are and which group or class they belong to. Finally, the third facet engages the psychological risk triggered when a consumer feels out of step with other members of the group.

Consumers who perceive social risk feel that members of their social group have expectations about how they should behave (Burnkrant and Cousineau, 1975). These expectations are not necessarily real; they may be diverse and may emanate from several different groups. Beliefs about the environmental concern of significant others are likely to be interpreted as one of these social expectations. Therefore, by ascribing a strong environmental concern to significant others, consumers assess the extent to which the choice of a harmful product is likely to deteriorate relationships by disappointing entourage's expectations. ECARO will therefore activate social risk perceptions. The assumption is that consumers would be encouraged to comply, at least in appearance, with the pro-ecological norm and to adopt proenvironmental actions (even without being convinced of their value) in order to maintain their relationship with significant others.

The perception of a social risk associated with non-ecological behaviour therefore has a central function in the process of influence. Even with consumers aware of their relevant others environmentalism, if no social risk is involved, they feel no obligation to avoid harmful products. Therefore, perceived social risk is expected to play a mediating role between ascriptions of environmental concern and pro-environmental decisions. The following hypothesis is proposed: 
H2: Perceived Social Risk associated with non-ecological choice (PSR) mediates the relationship between ECARO and the probability of choosing a product with a low rather than a high environmental impact.

\section{The mediating role of self-image / product-image consistency}

Possessions act as an extension of the self (Belk, 1988), in case of internalization, individuals will tend to reject any object that has negative environmental consequences so as not to be associated with it. Pro-environmental consumption serves both individualistic needs and social needs related to the symbolic value of goods in terms of belongingness and social identity (Griskevicius et al., 2010). It may be viewed as a way of achieving social compatibility and expressing social identity.

But to some extent, consumers' identity is shaped by social networks. They influence the way people think and (as a result) the way they consume. An entire generation of scholars has examined the role of social environment on ideological elaboration based invariably on the same premise: the social environment is paramount in explaining attitudes and beliefs (Christakis and Fowler, 2009). Regular contact with people concerned about the environment should progressively lead consumers to internalize environmental preservation as an important decision criterion. Nevertheless, this evolving process is not easy to capture since environmental ideology may be both an outcome of social network interactions and an implicit homophilous rationale for network building. People like to surround themselves with individuals who share their fundamental beliefs and attitudes. For this reason, it may be difficult to understand the underlying reinforcing dynamic between the perceived environmental concern of others and one's own concern. However, the effect is invariably the same: consumers will be more concerned about the environment when significant others are 
also concerned, either because they have internalized these convictions or because they have created social ties with similar people. Either way, the internalized norm is part of who they are. This process is consistent with Schwartz's Norm Activation Model, which states that personal norms are determined by social norms (Schwartz, 1977). Contrary to the compliance and identification processes, internalization influences behaviour in a deeper and less superficial way since individuals appropriate the norm. Therefore, adopting the proenvironmental choice reflects their self-identity. One way of overcoming the difficulty of grasping the progressive internalization process would be to capture it through the examination of self-concept. It is generally agreed that the way consumers perceive themselves tends to influence their purchasing behaviour, particularly when the product in question has a symbolic meaning and the individual identifies with this symbol (e.g. Grubb and Grathwohl, 1967; White and Dahl, 2007; Paharia et al, 2011).

If a product is known for having specific attributes that convey an identifiable positive symbolic meaning, by purchasing this product, the individual transfers these attributes to himself/herself, thereby enhancing his/her self-concept (Grubb and Grathwohl, 1967). Reciprocally, any product that conveys a negative identifiable symbolic meaning is likely to be rejected to avoid being associated with its negative attributes. The decision not to purchase items viewed as inconsistent with self-concept is a way of guaranteeing self-consistency (Sirgy, 1982). Therefore, if a consumer perceives a non-ecological product as being inconsistent with his/her self-image and lifestyle, he/she will tend to avoid it and to prefer the less environmentally harmful alternative. However, it is important to note that group membership and the reactions of significant others influence- and are even part of - selfconcept (Grubb and Grathwohl, 1967, White and Dahl, 2007). Thus, the ecological beliefs of significant others are likely to influence self-image related to pro-environmental consumption. As a result, a product that is inconsistent with the pro-environmental social norm will also be 
perceived as conflicting with self-image and will be avoided. The following hypothesis is proposed:

H3: Self-image/product-image incongruity mediates the relationship between ECARO and the probability of choosing a product with a low rather than a high environmental impact.

Figure 1. Pattern of hypotheses

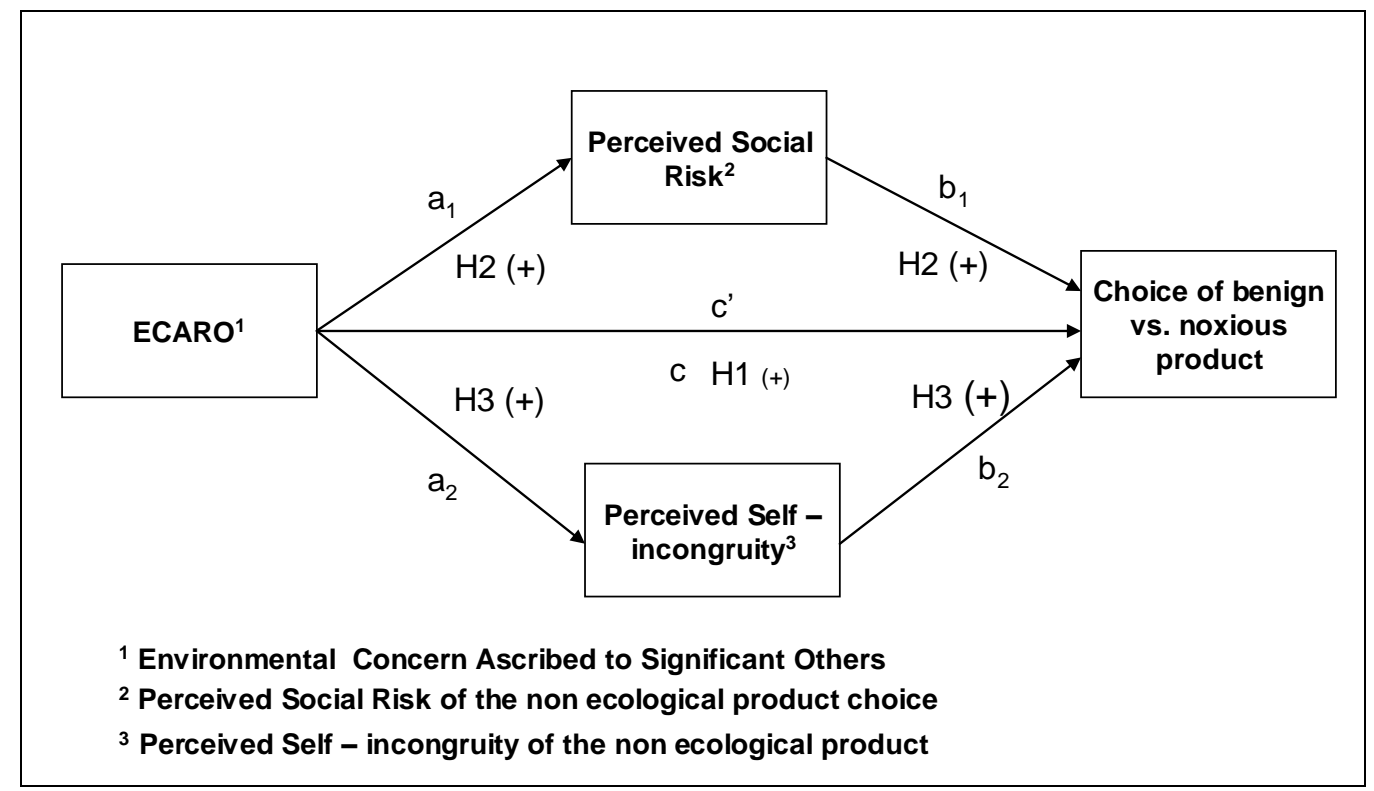

\section{Method}

The data are based on a questionnaire survey conducted as part of this research. Data collection was conducted in several regions of France. The exploitable sample consists of 468 interviewees. No strict quota was imposed, although specific indications were given to obtain a well-balanced sample in terms of gender, age and educational level. 
The pro-environmental decision: choosing a product with a low rather than a high environmental impact

Ecologically responsible consumption does not necessarily entail buying green labelled products. However, some skills are required to see that certain choices are clearly more harmful to the environment than others. By a process of elimination, environmentally responsible consumers will tend to choose the least harmful solution (even if it is not a perfect solution) (Steg and Vlek, 2008).

This explains why respondents were required to choose between two options: a fashionable product that is also environmentally objectionable, i.e. an espresso machine using aluminum capsules $^{\mathrm{i}}$ and a comparable classic but ecologically friendlier espresso machine that uses raw or ground coffee in filter bags. Despite recycling programs, capsule machines are intrinsically harmful to the environment. They generate significantly more waste and recycling aluminum capsules is an expensive and complex process. Therefore, the decision to opt for the traditional espresso machine and to avoid the capsule machine was clearly the proenvironmental decision. Nevertheless, the potentially harmful environmental effects of the capsule machine were not brought to the attention of respondents, who could complete the entire questionnaire without ever being aware of the effects of the machine.

The general characteristics of the machines were adjusted to make the alternatives comparable in terms of technical features, brand, price, colour and design. The devices differed mainly in terms of environmental impact. However the ecological attribute was not made too salient in order to avoid socially desirable responding.

Thanks to screening questions, only individuals who are likely to be involved in such a decision (espresso machine owners and consumers who contemplated buying one) were included in the survey. Respondents were notified in a hypothetical scenario that their home 
espresso machine had recently broken down and that they needed to replace it. Respondents were also informed that they had identified two similar models in a large appliance store. Each model was chosen by approximately half of the sample $(50.2 \%$ opted for the traditional espresso machine).

\section{Designation of relevant others and ascription of environmental concern}

An elicitation method was used to help respondents identify their relevant others, as recommended by Ajzen (1991) in developing TPB questionnaires. The following instruction was given to respondents: "Some of your friends, family members, colleagues, relatives, etc. would be likely to make a judgment (whether positive or negative) about your choice of espresso machine. Think of the four most important people among them, write their initials, and for each one of them, please answer the following questions". The number of relevant others was restricted to four to avoid the fatigue factor inherent in long questionnaires. Pretests conducted on 102 French undergraduate students validated this option. In the pretest, the number of designated ties was free. On average, students made 4.2 quotations with a standard deviation of just 1.2. Most of the elicited important others were friends, parents, siblings, spouses and colleagues.

Ascribed environmental concern was measured by asking respondents to rate their level of agreement with four statements based on a seven-point Likert scale (from 1= totally disagree to $7=$ totally agree). The items were mixed with other attribution scales to measure ascribed involvement with coffee and ascribed novelty-seeking. These additional questions were designed to avoid an excessive focus on ecology but they also served as control variables since they represented alternative explanations for social risk and perceived incongruity. For example, ascribed novelty-seeking is likely to explain social risk and incongruity. Since aluminum capsule espresso machines are fashionable, fashion sensitive relevant others are 
likely to implicitly exert greater pressure to buy this particular type of coffee machine. In the same way, as a result of massive communication campaigns, owning the aluminum capsule system may be viewed as a way of enhancing self-image. The number of capsule machine owners among the designated relevant others was controlled to take into account a simple imitation effect. The measurement scales were based on existing scales and adapted to the interpersonal context. For example, the ECARO scale was derived from the scale used by Kilbourne and Pickett (2008). Since respondents were required to answer the same questions four times, the scales were deliberately shortened. All of the scales were pretested on the undergraduate student sample. Exploratory analyses show evidence of satisfactory psychometrics (See table 1). The ECARO score is the simple arithmetic mean of the four factor scores, one per relevant quoted referral, extracted based on Principal Component Analysis. The same method was used for the controlled variables.

Table 1. Attribution variables measurement

\begin{tabular}{|c|c|c|}
\hline Variables & Items & $\begin{array}{c}\text { Cronbach's } \\
\text { Alpha }\end{array}$ \\
\hline ECARO $^{\mathrm{a}}$ & $\begin{array}{l}\text { Person 1... Item 1: would be willing to } \\
\text { reduce his/her consumption to help protect the } \\
\text { environment; Item 2: is very concerned about } \\
\text { environmental problems; Item 3: thinks that } \\
\text { consumers do not make sufficient efforts to } \\
\text { preserve the environment; Item 4: buys } \\
\text { environmentally friendly products whenever } \\
\text { possible. }\end{array}$ & $\begin{array}{l}\text { From } 0.87 \text { to } \\
0.89\end{array}$ \\
\hline Ascribed Novelty-Seeking & $\begin{array}{l}\text { Person 1... Item 1: is very sensitive to fashion } \\
\text { trends; Item 2: likes to try new products; Item } \\
\text { 3: is always aware of latest trends. }\end{array}$ & $\begin{array}{l}\text { From } 0.83 \text { to } \\
0.86\end{array}$ \\
\hline $\begin{array}{l}\text { Ascribed involvement with } \\
\text { coffee drinking }\end{array}$ & $\begin{array}{l}\text { Person 1... Item 1: attaches particular } \\
\text { importance to coffee; Item 2: is a true coffee } \\
\text { lover. }\end{array}$ & $\begin{array}{l}\text { From } 0.84 \text { to } \\
0.86\end{array}$ \\
\hline
\end{tabular}

${ }^{\mathrm{a}}$ Environmental Concern Ascribed to Relevant Others 


\section{Other controlled variables}

A number of beliefs about the machines were controlled, especially awareness of the negative environmental consequences of decisions (ANEC). ANEC was measured by a single item mixed with other beliefs (see table 2). The additional questions were integrated for the same reasons as the additional attribution variables since they partially concealed the objectives of the study and represented alternative explanations for choosing (or not choosing) the capsule machine.

Table 2. Beliefs about using the capsule machine

\begin{tabular}{|c|c|c|c|}
\hline $\begin{array}{l}\text { Beliefs about the } \\
\text { capsule machine }\end{array}$ & Items & Mean & SD \\
\hline 1. ANEC ${ }^{\mathrm{a}}$ & $\begin{array}{l}\text { By comparison with the second espresso machine, } \\
\text { using the [aluminum capsule machine] is harmful to the } \\
\text { environment. }\end{array}$ & 4,28 & 1,88 \\
\hline $\begin{array}{l}\text { 2. Better coffee } \\
\text { taste }\end{array}$ & $\begin{array}{l}\text { By comparison with the second espresso machine, } \\
\text { using the [aluminum capsule machine] produces better } \\
\text { coffee }\end{array}$ & 4,07 & 1,99 \\
\hline 3. Easy use & $\begin{array}{l}\text { By comparison with the second espresso machine, } \\
\text { using the [aluminum capsule machine] is easier }\end{array}$ & 4,81 & 1,93 \\
\hline $\begin{array}{l}\text { 4. Long-term } \\
\text { expenses }\end{array}$ & $\begin{array}{l}\text { By comparison with the second espresso machine, } \\
\text { using the [aluminum capsule machine] is more } \\
\text { expensive in the long term. }\end{array}$ & 5,46 & 1,72 \\
\hline $\begin{array}{l}\text { 5. Belonging to a } \\
\text { "club" }\end{array}$ & $\begin{array}{l}\text { By comparison with the second espresso machine, } \\
\text { using the [aluminum capsule machine] makes you feel } \\
\text { like you are part of a club }\end{array}$ & 4,05 & 2,14 \\
\hline
\end{tabular}




\section{Perceived social risk and self-incongruity}

Although several measurement scales of social risk can be found in the literature, they fail to capture the concept's nuances. To improve content validity, a new scale was created to measure the three facets referred to above. After qualitative and quantitative pretests, all six items were kept. Exploratory and confirmatory analyses were conducted and showed satisfactory results. Despite the three identified theoretical facets of social risk, the concept appears to be one-dimensional. In the final data collection, the confirmatory model estimated using the Maximum Likelihood method fits the data correctly (GFI=.93; AGFI=.92; RMSEA $=0.099$ with a $90 \%$ interval $\left.=[.063 ; .132], \mathrm{Chi}^{2} / \mathrm{df}=2.63\right]$. The scale is reliable (Jöreskog's rho $=.92)$ and has a good convergent validity (convergent validity rho $=0.72$ ) Self-incongruity was captured using the method recommended by Sirgy et al. (1997) by two items adapted from their study and converted to a semantic differential format (see table 3 ).

Table 3. Measures of perceived social risk and self-incongruity

\begin{tabular}{|c|c|c|}
\hline Variables & Items & $\begin{array}{c}\text { Cronbach's } \\
\text { Alpha }\end{array}$ \\
\hline $\begin{array}{l}\text { Perceived } \\
\text { social risk }\end{array}$ & $\begin{array}{l}\text { I fear that if I choose the [aluminum capsule machine],... } \\
\text { - I'll be criticized by people around me; } \\
\text { - people around me will be disappointed; } \\
\text { - people around me will misinterpret my way of thinking; } \\
\text { people around me will be wrong about what I am } \\
\text { - I will no longer be on the same wavelength as people whose } \\
\text { opinion matters to me; } \\
\text { - I will be out of step with the values of people whose } \\
\text { opinion matters to me } \\
\text { (7-point Likert Scales) }\end{array}$ & 0,92 \\
\hline $\begin{array}{l}\text { Self- } \\
\text { incongruity }\end{array}$ & $\begin{array}{l}\text { By comparison with the second espresso machine, using the } \\
\text { [aluminum capsule machine], ... } \\
\text { - would be totally consistent (1) / totally inconsistent (7) } \\
\text { with how I see myself } \\
\text { - would totally reflect (1) / would not reflect at all (7) who I } \\
\text { am } \\
\text { (7-point SD scales) }\end{array}$ & 0,88 \\
\hline
\end{tabular}




\section{Results}

Since the dependent variable is dichotomous, binary logistic regression was used to test the research hypotheses. The tests of the mediation hypotheses involved an examination of the significance of indirect effects based on a bootstrap analysis. Given that the model included two mediators, the method developed by Preachers and Hayes (2008) to test mediation with multiple mediators for binary outcomes was used.

As noted above, several controlled variables were introduced in the model: ascribed involvement and novelty-seeking, number of capsule machine owners among relevant others, and the five beliefs about using this system. For homogenization purposes, the variables were standardized. The correlation matrix is given in table 4. There was no problem of multicollinearity between the explanatory variables. The two mediators, i.e. social risk and self-incongruity, are not significantly correlated, indicating that both paths may represent distinct mechanisms through which ECARO influences choice.

Table 4. Correlation matrix

\begin{tabular}{|c|c|c|c|c|c|c|c|c|c|c|}
\hline & (1) & (2) & (3) & (4) & (5) & (6) & (7) & (8) & (9) & (10) \\
\hline (1) ECARO & 1.00 & & & & & & & & & \\
\hline (2) Social risk & $.26 * *$ & & & & & & & & & \\
\hline $\begin{array}{l}\text { (3) Self- } \\
\text { Incongruity }\end{array}$ & $.13 * *$ & .04 & & & & & & & & \\
\hline $\begin{array}{l}\text { (4) Ascribed } \\
\text { Novelty-Seeking }\end{array}$ & -.02 & -.03 & -.08 & & & & & & & \\
\hline $\begin{array}{l}\text { (5) Ascribed } \\
\text { involvement }\end{array}$ & $.14 * *$ & .07 & -0.05 & .01 & & & & & & \\
\hline (6) $\mathrm{ANEC}^{\mathrm{a}}$ & $.14 * *$ & $.13^{* *}$ & .01 & .05 & .08 & & & & & \\
\hline $\begin{array}{l}\text { (7) "Better coffee } \\
\text { taste" }\end{array}$ & -.02 & -.06 & $-.44 * *$ & $.11^{*}$ & .06 & .05 & & & & \\
\hline (8) "Easier use" & .05 & .02 & $-.34 * *$ & $.13 * *$ & .07 & .03 & $.51 * *$ & & & \\
\hline $\begin{array}{l}\text { (9) "Long-term } \\
\text { higher expenses", }\end{array}$ & $.10^{*}$ & .05 & .03 & -.03 & .03 & $.30 * *$ & $.19 * *$ & .22 & & \\
\hline $\begin{array}{l}\text { (10) "Belonging to } \\
\text { a club" }\end{array}$ & .06 & $.22 * *$ & -.07 & $.17 * *$ & .01 & $.11^{*}$ & .04 & $.13^{*}$ & .11 & \\
\hline $\begin{array}{l}\text { (11) Number of } \\
\text { owners }\end{array}$ & .01 & .05 & $-.16^{* *}$ & .05 & $.14 * *$ & .07 & .03 & .06 & .01 & $.18 * *$ \\
\hline
\end{tabular}


Direct (or total) effect of ECARO - The results of the binary logistic regression (table 5) show that ECARO significantly increases the probability of choosing the traditional espresso machine (the environmentally neutral product) rather than the aluminum capsule machine (Path c fig. 1: $\mathrm{B}=.45, \mathrm{p}=.006$ ). This result supports $\mathrm{H} 1$ and confirms that among the beliefs attributed to significant others, environmental concern plays a role in consumer choices in the same way (for example) as novelty-seeking, which increases the probability of choosing the capsule machine $(\mathrm{B}=-.51 ; \mathrm{p}=.005)$. It is also interesting to note that ascribed environmental concern influences decision-making only through interpersonal influence mechanisms. ANEC has no significant effect on decisions $(\mathrm{B}=.12 ; \mathrm{p}=.318)$, indicating that individual beliefs about product harmfulness are not efficient motivations for avoiding harmful products.

Table 5. Total effect of ECARO, results of binary logistic regression

\begin{tabular}{|c|c|c|c|c|}
\hline \multicolumn{5}{|c|}{ Dependent variable: low impact vs. high impact choice } \\
\hline & $\mathrm{B}$ & S.E. & Wald & $\operatorname{Exp}(B)$ \\
\hline ECARO & $\mathrm{c}=.45^{* *}$ & .17 & 7.47 & 1.57 \\
\hline Ascribed Novelty-Seeking & $-.51 * *$ & .18 & 7.89 & .60 \\
\hline Ascribed involvement & $.36^{*}$ & .18 & 3.95 & 1.44 \\
\hline $\mathrm{ANEC}^{\mathrm{a}}$ & .12 & .11 & 1.06 & 1.12 \\
\hline "Better coffee taste" & $-.81 * *$ & .13 & 38.44 & .44 \\
\hline "Easier use" & -.14 & .13 & 1.24 & .87 \\
\hline "Long-term higher expenses" & $.48 * *$ & .12 & 16.69 & 1.62 \\
\hline "Belonging to a club" & -.03 & .11 & .07 & .97 \\
\hline Number of owners & -.14 & .24 & .35 & .87 \\
\hline Constant & .09 & .12 & .62 & 1.10 \\
\hline Nagelkerke $\mathrm{R}^{2}$ & & & & \\
\hline Hosmer- Lemeshow $\mathrm{Chi}^{2}$ (df) & & & $(8)$ & \\
\hline
\end{tabular}

Mediation effects of self-incongruity and perceived social risk - The effect of ECARO on both mediators was estimated (paths a1 and a2, figure 1) through OLS linear regression. The results are shown in table 6. ECARO has a significant positive influence on both social risk 
$\left(\mathrm{a}_{1}: \mathrm{B}=.18 ; \mathrm{p}=.006\right)$ and self-incongruity $\left(\mathrm{a}_{2}: \mathrm{B}=.34 ; \mathrm{p}<.001\right)$. From a social influence point of view, a number of comments can be made about the effects of controlled variables. First, ECARO is the only common mechanism leading to both self-incongruity and social risk. Naturally, individual beliefs about products determine self-incongruity either negatively or positively. However, they do not modify social risk perceptions. The belief that owning the capsule espresso machine results in membership of a kind of club is a notable exception (B $=.20 ; \mathrm{p}=.002)$. Through this belief, consumers tend to allocate a normative power to the product related to the feeling of being part of or excluded from an entity.

Finally, the perception of self-incongruity is based on representations of product-users. These representations are shaped by the structure of consumers' social networks. The number of capsule machines owners among referent others has a strong influence on perceived selfincongruity $(B=-.30 ; \mathrm{p}<.001)$.

Table 6. Effect of ECARO on mediators, results of OLS regression

\begin{tabular}{lcccc}
\hline & \multicolumn{2}{c}{$\begin{array}{c}\text { Dependant variable: } \\
\text { social risk of harmful } \\
\text { choice }\end{array}$} & $\begin{array}{c}\text { Dependant } \\
\text { variable: } \\
\text { self-incongruity of } \\
\text { the harmful product }\end{array}$ \\
\hline & $\mathrm{B}$ & $\mathrm{SE}$ & $\mathrm{B}$ & $\mathrm{SE}$ \\
\hline ECARO & $\mathrm{a}_{1}=.34 * *$ & .068 & $\mathrm{a}_{2}=.18^{* *}$ & .062 \\
Ascribed Novelty-Seeking & -.09 & .073 & .01 & .067 \\
Ascribed involvement & .05 & .075 & -.04 & .068 \\
ANEC" & .08 & .046 & -.01 & .042 \\
"Better coffee taste" & -.07 & .052 & $-.37 * *$ & .047 \\
"Easier use" & .03 & .052 & $-.17 * *$ & .048 \\
"Long-term higher expenses" & -.02 & .048 & $.13 * *$ & .043 \\
"Belonging to a club" & $.20 * *$ & .046 & -.03 & .042 \\
Number of owners & .01 & .105 & $-.30 * *$ & .095 \\
Constant & .01 & .049 & .06 & .045 \\
\hline & $\mathrm{F}(9 ; 455)=6.94 * *$ & $\mathrm{~F}(9 ; 455)=$ \\
& \multicolumn{3}{c}{$\mathrm{R}^{2}=.12$} & \multicolumn{2}{c}{$18.09 * *$} \\
\hline
\end{tabular}

$* * \mathrm{p}<.01 * \mathrm{p}<.05$ 
The effects of mediators on neutral vs. harmful choice b1 and b2 are assessed by adding social risk and self-incongruity to the binary logistic model shown in table 5. The results are shown in table 7.

As expected, social-risk $\left(\mathrm{b}_{1}: \mathrm{B}=.47 \mathrm{p}<.001\right)$ and self-incongruity $\left(\mathrm{b}_{2}: \mathrm{B}=1.09 \mathrm{p}<.001\right)$ are significant and have positive effects. When the prospect of choosing the aluminium capsule machine generated social risk or was viewed as self-incongruent, consumers tended to prefer the other espresso machine.

Indirect effects $a_{1} * b_{1}$ and $a_{2} * b_{2}$ are estimated from 5000 bootstrap samples. Both are significant. For self-incongruity, the mean value of $a_{1} * b_{1}$ is equal to .21 with a $95 \%$ confidence interval excluding 0 (.05 to .37). For social risk, the average value of $a_{2} * b_{2}$ is equal to .17 also with a $95 \%$ confidence interval excluding $0(.07$ to .30$)$ (see table 8$)$. These results confirm that ascription of high environmental concern to significant others encourages consumers to avoid environmentally harmful choices through two mechanisms: social risk reduction and the internalization of environmental values. The results also support $\mathrm{H} 2$ and $\mathrm{H} 3$. Moreover, when mediator variables are uncorrelated, it is recommended to calculate contrast statistics for indirect effects. The null hypothesis is that indirect effects have the same magnitude. The average value of the contrast coefficient is equal to .04 with a $95 \%$ confidence interval that includes 0 (-.16 to .23). Therefore, the null hypothesis cannot be rejected. Both indirect effects have the same weight. For the entire sample, social-risk reduction and internalization mechanisms are equally involved in harmful product avoidance. Moreover, ECARO is not significant when social risk and self-incongruity are controlled (c': $\mathrm{B}=.25 ; \mathrm{p}=.183)$. This corresponds to "indirect-only" mediation (Zhao et al., 2010) and indicates that social risk and self-incongruity capture the entire effect of ECARO on a neutral 
rather than a harmful choice. This result suggests that it is highly unlikely that mediators have been omitted (Zhao et al., 2010).

Ascribed environmental concern and novelty-seeking may both be interpreted as social norms by consumers. Ascribed novelty-seeking significantly increases the probability of choosing the most innovative espresso machine $(B=-.51 ; \mathrm{p}=.005)$ but does not significantly influence either social risk $(B=-.09 ; p=.203)$ or self-incongruity $(B=.01 ; p=.906)$. These results highlight the specificity of normative social influence in the specific case of ecological issues: interpersonal influence is based on an anticipation of negative social consequences and value internalization.

Table 7. Effects of self-incongruity and social risk, results of binary logistic regression

\begin{tabular}{|c|c|c|c|c|}
\hline \multicolumn{5}{|c|}{ Dependent variable: low impact vs. high impact choice } \\
\hline & & & & $\operatorname{Exp}(B$ \\
\hline & $\mathrm{B}$ & S.E. & Wald & ) \\
\hline ECARO & $\mathrm{c}^{\prime}=.25$ & .186 & 1.77 & 1.28 \\
\hline Ascribed Novelty-Seeking & $-.55^{* *}$ & .199 & 7.62 & .58 \\
\hline Ascribed involvement & $.49 *$ & .203 & 5.79 & 1.63 \\
\hline $\mathrm{ANEC}^{\mathrm{a}}$ & .134 & .124 & 1.15 & 1.14 \\
\hline "Better coffee taste" & $-.53 * *$ & .144 & 13.26 & .59 \\
\hline "Easier use" & -.06 & .142 & .15 & .95 \\
\hline $\begin{array}{l}\text { "Long-term higher } \\
\text { expenses" }\end{array}$ & $.47 * *$ & .128 & 13.26 & 1.60 \\
\hline "Belonging to a club" & -.05 & .122 & .19 & .95 \\
\hline Number of owners & .09 & .272 & .12 & 1.10 \\
\hline Self-incongruity & $\mathrm{b}_{2}=1.09 * *$ & .155 & 50.13 & 2.99 \\
\hline Social risk & $\mathrm{b}_{1}=.47 * *$ & .131 & 12.78 & 1.60 \\
\hline Constant & .07 & .128 & .29 & 1.07 \\
\hline Nagelkerke $\mathrm{R}^{2}$ & & .41 & & \\
\hline $\begin{array}{l}\text { Hosmer-Lemeshow Chi² } \\
\text { (df) }\end{array}$ & & $8.73(8)$ & & \\
\hline
\end{tabular}


Table 8. Synthesis of direct and indirect effects

\begin{tabular}{|c|c|c|c|c|}
\hline & B & SE & Significance & Conclusion \\
\hline Total effect c & .45 & .16 & .006 & H1 supported \\
\hline $\begin{array}{l}\text { Indirect effect } a_{1} b_{1} \\
\quad \text { (social-risk) }\end{array}$ & $\begin{array}{c}.17 \\
\text { (Mean with } 5000 \\
\text { bootstrap } \\
\text { samples) }\end{array}$ & .06 & $\begin{array}{c}.07 ; .30] \\
(95 \% \text { confidence } \\
\text { interval excluding } 0)\end{array}$ & H2 supported \\
\hline $\begin{array}{l}\text { Indirect effect } \mathrm{a}_{2} \mathrm{~b}_{2} \\
\text { (self-incongruity) }\end{array}$ & $\begin{array}{c}.20 \\
\text { (Mean with } 5000 \\
\text { bootstrap } \\
\text { samples) }\end{array}$ & .08 & $\begin{array}{c}{[.05 ; .36]} \\
(95 \% \text { confidence } \\
\text { interval excluding } 0)\end{array}$ & H3 supported \\
\hline $\begin{array}{c}\text { Contrast self- } \\
\text { incongruity / social } \\
\text { risk }\end{array}$ & $\begin{array}{c}.04 \\
\text { (Mean with } 5000 \\
\text { bootstrap } \\
\text { samples) }\end{array}$ & .09 & $\begin{array}{c}{[-.15 ; .23]} \\
\text { confidence interval } \\
\text { including } 0)\end{array}$ & $\begin{array}{l}\text { No difference of } \\
\text { magnitude between } \\
\text { indirect effects }\end{array}$ \\
\hline Direct effect c' & .25 & .19 & .183 & $\begin{array}{l}\text { "indirect-only" } \\
\text { mediation }\end{array}$ \\
\hline
\end{tabular}

\section{Discussion and implications}

\section{Summary and major contributions}

The purpose of this study was to examine consumer pro-environmental decision-making when faced with a choice between an environmentally unfriendly product and a more neutral alternative. This choice is relevant since green purchasing usually involves a decision to avoid products that harm the environment in favour of products with a limited carbon footprint. This approach is a major contribution of our research. While most studies tend to oppose environmentally friendly to environmentally unfriendly behaviours, this paper argues that ecological decisions are rarely as simplistic or manichean and that the opposition between harmful and neutral products or behaviours is more realistic.

A normative perspective was adopted to understand the process leading to pro-environmental decisions. Social influence was limited to influence from special members of participants' social network, i.e. relevant others. The central assumption developed in this paper is that 
individuals who believe that their relevant others are concerned about environmental issues will tend to avoid environmentally unfriendly products. Capturing the effect of social influence in this way is the second contribution of this study. Previous work on the determinants of ecological behaviour essentially examined individual variables, with a particular emphasis on attitudinal variables.

Prior to this study, no research had been conducted on the effect of environmental concern ascribed to members of the consumer's social group. As for studies dealing with the role of social influence on ecological behaviour, they are relatively rare and often imply measuring social norms through general items about what other people are likely to approve of. The approach used in this paper avoids a frontal acknowledgment of normative influence by respondents. This is consistent with the idea that social influence is under-detected rather than explicitly recognized (Nolan et al., 2008).

The results of this study confirm that environmental concern ascribed to relevant others influences individual behaviour and results in choosing an environmentally neutral product over an environmentally harmful product. This process was shown to be mediated by perceived social risk and self-incongruity associated with the harmful product. The two paths of influence described in this paper constitute a third contribution of this research. One of the key inputs lies in the conceptualization and measurement of the concept of perceived social risk. Although there is an abundant literature relating to perceived risk, the social dimension of the construct is often neglected. This paper provides one possible definition, i.e. the anticipation of negative social outcomes associated with a particular consumption, as well as a new measurement scale of perceived social risk.

From a methodological point of view, the research design of this study helped to reduce the effects of the social desirability bias since pro-environmental attributes were never explicitly 
brought to participants' attention. This approach has two advantages. First, since environmental labelling is not widespread (Borin et al., 2011) and often basic, the approach used in this paper reflects a relatively realistic situation. Consumers seeking to minimize the impact of their consumption need to make daily choices based on their own appreciation. Second, unlike most previous studies, the absence of specific environmental indications avoids a bias that might result in an artificial preference for the pro-environmental product.

\section{Limitations and future perspectives}

Despite the contributions of this study, the results must be analyzed with caution. First, the product category (i.e. coffee machines) targeted in the survey is highly specific and relatively high-involving. Yet most pro-environmental decisions are related to daily purchases. In addition, the theoretical model was only tested among a sample of French respondents. A replication of the study in other cultural contexts based on a new category of product or a different type of behaviour could be conducted to confirm the findings.

Another limitation related to product category is that, in France, drinking coffee is a socially shared cultural and habit. It is a common social convention to offer coffee to guests, which means that coffee machines generally involve public rather than private consumption. Previous work showed that private vs. public consumption is an important variable that determines choice (e.g. Ratner and Kahn, 2002). It is likely that perceived social risk plays a key role in purchases that include an inherent social dimension or that involve conspicuous consumption (such as the fashionable Espresso machine). However, avoiding social sanctions as an external motivation would probably not be relevant in the case of private consumption. Future research could assess the relative importance of social risk when dealing with private or public consumption. 
Future research could also examine decision-making in cases where consumers are subject to conflicting social pressures - for example if they believe that their relevant others have opposing beliefs. In this paper, ECARO was calculated for every respondent and corresponds to the average level of environmental concern attributed by participants to the three identified members of their social network. Nevertheless, some referents may exert a stronger influence than others. Therefore, it may be useful to identify relevant variables that could be used to introduce weightings in the calculation. Homogeneity vs. heterogeneity in terms of levels of environmental concern among relevant others could also be taken into account. The average values of overall ECARO scores correspond either to a homogeneous average value among all the referents or to a combination of low and high levels of environmental concern. The tests carried out as part of this research failed to generate any substantial results, although experimental approaches could be adapted to highlight the potential effects of the heterogeneity of beliefs ascribed to relevant others.

The mediating effect of perceived self-incongruity on ECARO and choice reflects another key facet of social influence. To some extent, social influence affects self-image, which in turn affects our decisions (e.g. Grubb and Grathwohl, 1967). People tend to feel that their choices reflect their personal norms, but personal norms are themselves shaped by social norms (Schwartz, 1977). Therefore, social norms appear to influence behaviour through two successive phases. First, we comply with social pressure and then we appropriate the norm. This refers to Kelman's process of internalization (Kelman, 1961). What was initially viewed as a constraint, i.e. avoiding a harmful product and complying with the environmental concern of relevant others in order to avoid social risk, thus becomes a personal preference. However, the process of internalization is difficult to capture for two reasons. First, internalization is an evolving process that occurs over time. Future research could use a longitudinal design to 
grasp the dynamics of this process. Second, it is difficult to determine whether people act like their significant others because they have internalized a social norm or because they bonded with their significant others as a result of sharing the same interests. Research has shown that individuals tend to share similar characteristics with their closest relations even in terms of beliefs, attitudes, and aspirations (Huston and Levinger, 1978). This occurs either because they choose to be surrounded by people who are like them based on the "similarity breeds fellowship" principle of homophily (McPherson et al, 2001) or because they embrace other people's beliefs or values and end up thinking the same way. It seems relatively difficult to dissociate pure internalization from homophilous network building. However, one promising research avenue would be to determine whether compliance and identification are stable motivations or if they are merely premises to norm internalization (Etzioni, 2000).

Finally, the results show that the two indirect paths through which ECARO influences choice are distinct and of equal weight. This suggests that preservation of self-concept and preservation of social ties represent, on average, two equally important motivations. However, future research should help to determine whether some consumers are more sensitive to one type of motivation or another depending on their profile.

\section{Managerial implications}

This research shows that consumers tend to act consistently with the beliefs and convictions of relevant others, either to preserve their social ties or to preserve their self-congruity. The findings suggest that environmentalists have a major social role to play in spreading environmentally responsible practices. Since the mere fact of believing that relevant others are concerned about environmental preservation induces pro-environmental behaviours, the issue is to facilitate the ascription of environmental concern. Therefore, environmentalists should be 
encouraged to express their convictions publicly within their social network. The first step would be to make them aware of their power of influence since most of them are probably not aware of their potential to affect other people's decisions. Companies selling green products and public authorities could promote pro-environmental behaviours by stimulating opinion leadership among environmentally responsible consumers. One way to do this would be to encourage going public about one's private ecological purchases in advertisements or to print messages on product packages such as "You are preserving the environment, tell your friends". First, this would help the attribution process. In order to make correct attributions about their friends' preferences, consumers need to know which opinions and convictions animate them. In turn, being aware of others' environmental concern may activate the process of norm internalization. Second, if environmentalists act as opinion leaders and share their expertise, they will provide their network with the necessary keys to identify environmentally harmful products. Opinion leadership, through which consumers convey both information about the environmental characteristics of products and a signal of their concern for the environment, can be a highly efficient means of enhancing eco-friendly behaviours within a social network.

\section{REFERENCES}

Ajzen, I. (1991), "The theory of planned behaviour", Organizational Behavior and Human Decision Processes, Vol. 50 No. 2, pp.179-211

Ajzen, I. (2006), “Constructing a TpB questionnaire: conceptual and methodological considerations", available at: http://www.people.umass.edu/aizen/tpb.html/. 
Armitage, C. J. and Conner, M. (2001), "Efficacy of the theory of planned behaviour: a metaanalytic review", British Journal of Social Psychology, Vol. 40 No. 4, pp. 471-501.

Balderjahn I. (1988), "Personality variables and environmental attitudes as predictors of ecologically responsible consumption patterns", Journal of Business Research, Vol. 17 No. 1 , pp. $51-56$

Bamberg S. (2003), "How does environmental concern influence specific environmentally related behaviors? A new answer to an old question", Journal of Environmental Psychology, Vol. 23 No. 1, pp. 21-32

Bang, H.-K., Ellinger, A. E., Hadjimarcou, J.S. and Traichal, P. (2000), “Consumer concern, knowledge, belief and attitude toward renewable energy: an application of the reasoned action theory, Psychology and Marketing, Vol. 17 No. 6, pp. 449-468.

Bauer R.A. (1960), “Consumer Behavior as Risk Taking”, in Hancock R.S. (Ed.), Dynamic marketing for a changing world, Proceedings of the 43rd Conference of the American Marketing Association, pp. 389-398.

Belk, R. W. (1988), "Possessions and the Extended Self”, Journal of Consumer Research, Vol. 15 No. 2, pp. 139-168.

Borin, N., Cerf, D. C. and Krishnan, R. (2011), "Consumer effects of environmental impact in product labeling”, Journal of Consumer Marketing, Vol. 28 No. 1, pp. 76-86.

Burnkrant, R. E and Cousineau, A. (1975), “Informational and normative social influence in Buyer Behavior”, Journal of Consumer Research: An Interdisciplinary Quarterly, Vol. 2 No. 3, pp. 206-215.

Christakis, N. A., and Fowler, J. H. (2009), Connected: The surprising power of our social networks and how they shape our lives, Little, Brown and Company, New-York, NY. 
Cialdini, R.B., Reno, R.R. and Kallgren, C.A. (1990), “A focus theory of normative conduct: recycling the concept of norms to Reduce littering in public places", Journal of Personality and Social Psychology, Vol. 58 No. 6, pp.1015-1026.

Deutsch M. and Gerard H B. (1955), “A study of normative and informational social influences upon individual judgment”, Journal of Abnormal Social Psychology, Vol. 51 No. 3, pp. 629-636.

Etzioni, A. (2000), "Social norms: internalization, persuasion, and history”, Law \& Society Review, 34, 1, 157-178

Granzin, K. L. and Olsen, J. E. (1991), “Characterizing participants in activities protecting the environment: a focus on donating, recycling and conservation behaviors", Journal of Public Policy and Marketing, Vol.10 No. 2, pp.1-27.

Griskevicius, V., Tybur, J. M., and Van den Bergh, B. (2010), “Going green to be seen: status, reputation, and conspicuous conservation”, Journal of Personality and Social Psychology, Vol. 98 No. 3, pp. 392-404.

Grubb, E.L and Grathwohl H.L (1967), “Consumer self-concept, symbolism and market behavior: a theoretical approach, Journal of Marketing, Vol. 31 No. 4, pp. 22-27.

Heath, Y., and Gifford, R. (2002), "Extending the theory of planned behavior: predicting the use of public transportation", Journal of Applied Social Psychology, Vol. 32 No. 10, pp. 2154-2189

Holt D.B. (1995)," How consumers consume: a typology of consumption practices", Journal of Consumer Research, Vol. 22 No. 1, pp.1-16.

Hopper, J. R., and Nielsen, J. M. (1991), "Recycling as altruistic behavior: normative and behavioral strategies to expand participation in a community recycling program", Environment and Behavior, Vol. 23 No. 2, pp. 195-220. 
Huston, T.L. and Levinger, G. (1978) “Interpersonal attraction and relationships”, Annual Review of Psychology, Vol. 29 No. 1, pp. 115-156.

Jacoby, J. and Kaplan, L. (1972), "The components of perceived $r$ isk”, In Venkatesan M. (ed.), Proceedings of the third annual conference of the Association for Consumer Research, College Park, Maryland : Association for Consumer Research, pp. 382-393.

Kaiser, F. G. and Fuhrer, U. (2003), “Ecological behavior's dependency on different forms of knowledge", Applied Psychology: An International Review, Vol. 52 No. 4, pp. 598-613.

Kelman, H. C. (1961), "Processes of opinion change”, Public Opinion Quarterly, Vol. 25 No. 1, pp. $57-78$

Kilbourne, W. and Pickett, G. (2008), "How materialism affects environmental beliefs, concern, and environmentally responsible behavior", Journal of Business Research, Vol. 61 No. 9 , pp. $885-893$

Kinnear T.C, Taylor, J.R. and Ahmed, S.A. (1974), "Ecologically Concerned Consumers: Who Are They?, Journal of Marketing, Vol. 38 No. 2, pp. 20-24.

Knussen, C., Yule, F., MacKenzie, J. and Wells, M. (2004), “An analysis of intentions to recycle household waste: the roles of past behaviour, perceived habit, and perceived lack of facilities", Journal of Environmental Psychology, Vol. 24 No. 2, pp. 237-246.

Krishnamurthi, L. (1983), "The salience of relevant others and its effect on individual and joint preferences: an experimental investigation”, Journal of Consumer Research, Vol. 10 No. 1, pp. 62-72.

Lee, J.A. and Holden, S.J.S., (1999), "Understanding the determinants of environmentally conscious behavior", Psychology and Marketing, Vol. 16 No. 5, pp. 373-392.

Ligas, M. (2000), "People, products, and pursuits: exploring the relationship between consumer goals and product meanings", Psychology \& Marketing, Vol. 17 No. 11, pp. 983-1003 
Lindenberg, S., and Steg, L. (2007), "Normative, gain and hedonic goal frames guiding environmental behavior, Journal of Social Issues", Vol. 63 No. 1, 117-137

McPherson, J.M., Smith-Lovin, L. and Cook, J.M. (2001), "Birds of a feather: homophily in social networks", Annual Review of Sociology, Vol. 27 No. 1, pp. 415-444

Nolan, J. M., Schultz, P. W., Cialdini, R. B., Goldstein, N. J., and Griskevicius, V. (2008), "Normative social influence is underdetected, Personality and social psychology bulletin", Vol 34 No. 7, pp. 913-23.

Paharia, N., Keinan, A., Avery, J., and Schor, J.B. (2011), "The underdog effect: the marketing of disadvantage and determination through brand biography", Journal of Consumer Research, Vol. 37 No. 5, pp. 775-790.

Park, C.W. and Lessig, V.P. (1977), “Students and housewives: differences in susceptibility to reference group influences”, Journal of Consumer Research, Vol. 4 No. 2, pp. 102-110.

Preacher, K. J., and Hayes, A. F. (2008), “Asymptotic and resampling strategies for assessing and comparing indirect effects in multiple mediator models", Behavior Research Methods, Vol. 40 No. 3, pp. 879-891.

Ratner, R.K., and Kahn, B.K. (2002), “The impact of private versus public consumption on variety-seeking behavior", Journal of Consumer Research, Vol. 29 No. 2, pp. 246-257.

Schwartz, S. H. (1977), "Normative influence on altruism”, in Berkowitz L. (Ed.), Advances in experimental social psychology, Vol. 10, pp. 221-279, New York: Academic Press.

Shrum, L.J., Lowrey T. M., and McCarty, J. A. (1994), Recycling as a marketing problem: a framework for strategy development”, Psychology \& Marketing, Vol. 11 No. 4, pp. 393416.

Sirgy, M.J. (1982), "Self-concept in consumer behavior: a critical review", Journal of Consumer Research, Vol. 9 No. 3, pp. 287-300. 
Sirgy, M. J., Grewal, D., Mangleburg, T. F., Park, J., Chon, K.-S., Claiborne, C.B., Johar, J.S. and Berkman, H. (1997), “Assessing the predictive validity of two methods of measuring self-image congruence”, Journal of the Academy of Marketing Science, Vol. 25 No. 3, pp. 229-241.

Sparks, P. and Shepherd, R. (1992), "Self-identity and the theory of planned behavior: assessing the role of identification with "green consumerism", Social Psychology Quarterly,Vol. 55 No. 4, pp. 388-399.

Steg, L., and Vlek, C. (2009), "Encouraging pro-environmental behaviour: an integrative review and research agenda", Journal of Environmental Psychology, Vol. 29 No. 3, pp. 309-317.

Stern, P. C. (2000), "Toward a coherent theory of environmentally significant behavior", Journal of Social Issues, Vol. 56 No. 3, pp. 407-424.

Schlegelmilch, B., Bohlen, G. and Diamantopoulos, A. (1996), “The link between green purchasing decisions and measures of environmental consciousness", European Journal of Marketing, Vol. 30 No. 5, pp. 35-55.

Schwepker, C. and Cornwell, T. (1991), “An examination of ecologically concerned consumers and their intention to purchase ecologically packaged products", Journal of Public Policy and Marketing, Vol. 10 No. 2, pp. 77-101

Tanner, C. and Kast, S. (2003), "Promoting sustainable consumption: determinants of green purchases by Swiss consumers", Psychology \& Marketing, Vol. 20 No. 10, pp. 883-902

Terry, D. J., Hogg, M. A., and White, K. M. (1999), "The theory of planned behaviour: selfidentity, social identity, and group norms", British Journal of Social Psychology, Vol. 38 No. 3, pp. 225-244. 
Thorbjørnsen, H., Pedersen, P.E. and Nysveen, H. (2007), “This is who I am: identity expressiveness and the theory of planned behavior", Psychology \& Marketing, Vol. 24 No. 9, pp. 763-785.

White, K. and Dahl, D.W. (2007), “Are all outgroups created equal? Consumer identity and dissociative influence”, Journal of Consumer Research, Vol. 34 No. 4, pp. 525-536.

Wind, Y. (1976), "Preference of relevant others and individual choice models", Journal of Consumer Research, Vol. 3 No. 1, pp. 50-57

Zhao, X., Lynch Jr., J. G., and Chen, Q. (2010), "Reconsidering Baron and Kenny: myths and truths about mediation analysis", Journal of Consumer Research, Vol. 37 No. 2, pp. 197206.

\footnotetext{
${ }^{i}$ In the questionnaire, the well-known brand of the machine was explicitly referred to both in the scenario and in the items. However, because this machine was the negative option, the brand name will not be given and the machine will be referred to instead as "aluminium capsule machine". The other option will be referred to as the second machine.
} 